\title{
COMPUTATIONAL APPROACH TO DESIGN ANTAGONISTS OF MYCOBACTERIUM TUBERCULOSIS LIPOPROTEIN LPRG (RV1411C) PROTEIN
}

\author{
ASIF HASSAN SYED ${ }^{* 1}$, TABREJ KHAN ${ }^{2}$, ARSHAD HASHMI ${ }^{2}$ \\ ${ }^{1}$ Department of Computer Science, Faculty of Computing and Information Technology, Rabigh, King Abdulaziz \\ University, Jeddah, Saudi Arabia \\ ${ }^{2}$ Department of Information Systems, Faculty of Computing and Information Technology, Rabigh, King Abdulaziz \\ University, Jeddah, Saudi Arabia \\ Email: shassan1@kau.edu.sa
}

Revised August 2016

ABSTRACT. Evolution of multi-drug resistance strains of Mycobacterium tuberculosis $(M T B)$ has in the past caused severe epidemics of tuberculosis across the globe thereby it raises a question on the potency or efficacy of the current scaffolds of drugs targeting MTB. Therefore, there an urgency to identify novel antimycobacterial compounds targeting proteins important for the viability of Multi-Drug-Resistant Tuberculosis (MDR-TB) strains. In this regard, Mtb LprG (Rv1411c) a lipoprotein involved in the elusion of cell-mediated immune response within infected host macrophages, is an important target for screening antimycobacterial compounds against Mtb. In the current study, a workflow comprising of virtual screening of ligand using USRCAT (Ultra Shape Recognition) and molecular docking protocols were employed to identify novel antituberculosis compounds. Based on USRCAT and docking studies XPX an analog of triacylated glycolipid was screened as a promising lead molecule that shows higher specificity and binding affinity for Mtb LprG protein. Further, in vitro experimentations are required to testify the role of XPX as an anti-TB drug for the treatment of MDT-TB.

Keywords: Multi-drug Resistant Tuberculosis; Toll-like receptor 2 (TLR2); antagonist; Molecular docking; Virtual screening

1. Introduction. Tuberculosis (TB) a highly infectious disease which continues to cause an alarming toll on a human being worldwide. In 2012, there were around 8.6 million TB cases were reported and the casualty 1.3 million approximately. Among these deaths, there were an estimated 170000 from Multidrug-Resistance Tuberculosis (MDR-TB), a relatively high total compared with 45000 cases of MDR-TB [1]. In this context, research effort to identify novel target specific antituberculosis compounds against diverse strains of $\mathrm{M}$. tuberculosis is an important step in combating the growing menace of MDR strains of Mycobacterium tuberculosis across the globe [2].

LprG (Rv1411c) lipoprotein is involved in the TLR2 depended on evasion of immune responses with host macrophages. The LprG protein acts as an agonist for TLR2 receptor protein and the efficacy of the TLR2-LprG interaction is enhanced by the formation of an intermediate complex between the LprG and triacylated glycolipids. The triacylated glycolipid binds precisely at the hydrophobic residues lining the cavity of H37Rv-LprG protein. The finding of a triacylated glycolipid in the hydrophobic pocket of LprG protein has vital effects on the role of LprG protein in the survival, persistence, and physiology of MTB in the host macrophages [3]. The encoding of p55 (Rv1410c) and LprG (Rv1411c) in a particular operon are significant for virulence [4-6]. Prolonged exposure of more than $16 \mathrm{~h}$ of human macrophages to H37Rv-LprG lipoprotein (TLR2 receptor acylated agonist) results in visible inhibition of MHC-II Ag processing. Furthermore, MHC-II Ag processing inhibition by H37Rv-LprG lipoproteins may permit survival of MTB within infected 
macrophages, by evading the innate immune reaction of the host [7].

Considering the critical role played by triacylated glycolipids in evading immune responses by enhancing the agonist activity of LprG protein, therefore screening antagonist molecules that bind specifically to the hydrophobic binding pocket of LprG lipoprotein. This antagonist-LprG protein interaction will cause inhibition of cell wall biogenesis, and TLR 2 agonist-mediated immune evasion of the host in tuberculosis infection.

Recently, conducted an analysis of the usage of computational techniques towards the discovery of drugs for TB, shows that the action of HTS against post-genomic antibacterial targets mostly has not been satisfactory. Moreover, the restricted chemical diversity of the screened collection and low druggability of antituberculosis targets also lead to poor efficiency of HTS [8-9]. Finally, these computational prototypes are used with negligible incorporation into the typical workflow of drug discovery for TB [10]. Moreover, compound classification methods and machine learning have been rarely put into practice. These methods are particularly operative for the computer-generated collection of libraries [11-12]. In spite of the fact that there is a crucial need for new alternative medicines [13-14], there has hardly been any new breakthrough in past 40 years except for the newly accepted bedaquiline for multidrug-resistant TB [15] However, there are other upcoming medicines undergoing medical trials.

In this regard, ligand-based virtual screening protocol USRCAT software [16-19] was used to identify ligand similar in structure to triacylated glycolipid (Ac1PIM2) and the ligand screened will be examined for their specificity and affinity for the hydrophobic ligand-binding domain (LBD) of LprG protein using AutoDock Vina 1.1.2 [20]. The crystal structure of H37RV-LprG protein [3] was used for performing the protein-ligand docking protocol. Finally, the highly specific antagonist ligands were obtained through computationally demanding docking scoring function analysis.

The present work is a step forward by our group to comprehend the computational approach developed to increase the efficiency of screening novel antagonists, binding specifically to a target site in a given protein. This project will help us to explore unconquered horizon in screening novel antituberculosis drugs binding specifically to Mtb LprG, from the vast molecular database available.

The paper is organized as follows. Section 2 is devoted methods used for screening antagonists of LprG protein. The results and discussion of the screening process are represented in Section 3. Section 4 highlight the concluding remarks of the present research work.

2. Methodology: In this section, we screened analogs from CREDO dataset using Ultra-Fast Shape Recognition (USRCAT) software and performed docking and toxicity studies to screen drug-like antagonist analog molecule.

- Screening database. We will use the CREDO dataset available online at http://www-cryst.bioc.cam.ac.uk/credo for screening structural interaction fingerprints of protein and ligand molecule similar to that of LprG protein and triacylated glycolipid (PIM2) complex.

- Shape similarity screen. USRCAT software was used for the shape similarity screening using the co-crystallized Mycobacterium tuberculosis LprG ligand (LprG-PIM2) as the search template (Ac1PIM2 from PDB code 3MHA) [3]. The similarity threshold of USRCAT was set to 0.9, in just 90 seconds using a quad-processing core of a laptop computer (including both reading descriptors from file and screening time). InstantJchem software was used to retrieve the 3D conformers corresponding to USR hits from the screening database.

- Ligand preparation. The structures downloaded from InstantJchem software were in .sdf format. OpenBabel (http://openbabel.org/wiki/Main_Page) software was used to convert the .sdf files to .mol2 format since autodock vina docking tool requires structural files in .mol2 format for performing molecular docking calculations. Ready to use dock prep structures of analogs of triacylated glycolipid were prepared using Chimera 1.10.

- Ligand Binding Site Preparation. The LprG protein in complex with acylated glycolipid was downloaded in .pdb format from RCSB PDB (PDB ID 3MHA). The binding region of the bounded agonist was defined as the binding site for virtual screening. The bounded agonist was defined as the center of the binding domain and the size of the binding position was set to a default value of $8 \AA$.

- Docking Virtual Screening Calculation. The resulting ligand obtained through USRCAT were docked will be docked into the hydrophobic pocket of the crystal structure of Mtb LprG lipoprotein (PDB CODE 3MHA) using AutoDock Vina 1.1.2. The crystal structure has a resolution of $2.0 \AA$. 
The molecular docking procedure was preset to rigid conditions and the docking grid was set to encompass the dimer interface of LprG-Ligand binding domain (LBD). The parameter exhaustiveness was preset to twenty while the remaining parameters were set to default standard values. All calculations were performed by the Intel Core i7 processor and Ubuntu 12.04 Operating System with a RAM of $8 \mathrm{~GB}$. The top-ranking chemical compounds were ordered based on the values of their binding affinity for LprG protein and the geometry and docking poses were examined. AutoDock Vina was used to generating docking poses, which were later loaded directly to Chimera. Chimera was employed to generate the pictures of the protein-ligands complex.

- Docking energy analysis. A high performing program, DSX (DrugScore eXtented) [21], was used to check the affinity of the screened antagonist molecule with LprG protein. The molecule, which has higher affinity, will have higher negative value.

- Toxicity Analysis. All the analogs of acylated glycolipid were subjected to toxicity prediction through ACD/Labs for all toxicity profiles like mutagenicity, carcinogenicity, irritant effects and reproductive effect. Toxicity analysis was done to know about the probable undesired effects of the drug in the body.

- PAIN-Remover Assay. The structural filters will be used to flag hits that might demonstrate a nonspecific activity these compounds were termed PAINS for Pan-Assay Interference compound [22]. We will use the most up-to-date version. It is noteworthy that the compound used for filtering may not include some of the useful molecules for further consideration. Indeed, it is enough for a member of a chemical series to be found promiscuous for all other members to be also considered promiscuous.

3. Results and Discussion. In this section, we describe the results of the ligand-based virtual screening, toxicity, and nonspecificity studies of the screened ligands.

Identification of potential lead antagonist molecules using shape-based screening (USRCAT),

Molecular Docking and DSX analysis. To identify potential lead compounds that display LprG antagonistic properties, CREDO database for atom pair fingerprints with Tanimoto similarity and trigram (LINGO) similarity were used to screen ligand similar to triacylated glycolipids (Ac1PIM2). Based upon atom pair fingerprint, trigram (LINGO) similarity and Lipinski criteria [23], we could screen four chemical component similar to triacylated glycolipid as shown in Table 1 and 2, respectively.

Table 1. Top-ranked similar chemical components using trigram (LINGO) similarity

\begin{tabular}{lllllllllll}
\hline $\begin{array}{l}\text { Sl. } \\
\text { No }\end{array}$ & Similarity & $\begin{array}{l}\text { HET- } \\
\text { ID }\end{array}$ & MW & $\begin{array}{l}\text { Heavy } \\
\text { Atoms }\end{array}$ & $\begin{array}{l}\text { Ring } \\
\text { Systems }\end{array}$ & $\begin{array}{l}\text { Aromatic } \\
\text { Ring } \\
\text { Systems }\end{array}$ & $\begin{array}{l}\text { Lipinski } \\
\text { HDB }\end{array}$ & $\begin{array}{l}\text { Lipinski } \\
\text { HBA }\end{array}$ & tPSA & XLogP \\
\hline $\mathbf{1}$ & 0.679 & DSU & 496 & 34 & 2 & 0 & 12 & 6 & 184. & 1.43 \\
\hline d2 & 0.615 & FUG & 459 & 33 & 2 & 0 & 7 & 1 & 108. & 3.92 \\
- & & & & & & & & & & 4 \\
\hline
\end{tabular}

Table 2. Top-ranked similar chemical components using trigram (LINGO) similarity

\begin{tabular}{lllllllllll}
$\begin{array}{l}\text { Sl. } \\
\text { No }\end{array}$ & Similarity & $\begin{array}{l}\text { HET- } \\
\text { ID }\end{array}$ & MW & $\begin{array}{l}\text { Heavy } \\
\text { Atoms }\end{array}$ & $\begin{array}{l}\text { Ring } \\
\text { Systems }\end{array}$ & $\begin{array}{l}\text { Aromatic } \\
\text { Ring } \\
\text { Systems }\end{array}$ & $\begin{array}{l}\text { Lipinski } \\
\text { HDB }\end{array}$ & $\begin{array}{l}\text { Lipinski } \\
\text { HBA }\end{array}$ & tPSA & XLogP \\
\hline $\mathbf{1}$ & 0.762 & XPX & 1134 & 77 & 3 & 0 & 23 & 11 & 370.6 & 6.4 \\
\hline $\mathbf{2}$ & 0.602 & UDG & 1016 & 68 & 3 & 1 & 23 & 8 & 358.0 & 3.77 \\
\hline
\end{tabular}

The chemical component screened through USR for their specificity and affinity for the hydrophobic ligand-binding domain of LprG protein using AutoDock Vina. Based upon the predicted binding free energies ( $\triangle$ Gvina) and $\mathrm{DSX}$ value, we observed that XPX ([(2R)-2,3-di(hexadecanoyloxy)propyl][(2S,3S,5S,6R)-3,4,5-trihydroxy-2,6-bis[[(2R,3S,4S,5R,6S)-3,4,5-trih ydroxy-6-(hydroxymethyl)tetrahydropyran-2-yl]oxy]cyclohexyl] phosphate]) showed minimum binding free energy value and larger negative score as compared to other ligands as represented in Table 3. 
Table 3. Docking energy and DSX analysis of the ligand-LprG protein complex

\begin{tabular}{llll}
\hline S1. No & Ligand & Free Binding Energy & DSX Score \\
\hline 1. & DSU & $-8.08 \mathrm{e}+006$ & -120.35 \\
\hline 2. & FUG & $-8.82 \mathrm{e}+006$ & -121 \\
\hline 3. & XPX & $-8.98 \mathrm{e}+006$ & -126 \\
\hline $\mathbf{4 .}$ & UDG & $-8.76 \mathrm{e}+006$ & -107.35 \\
\hline & PIM2 (Positive control) & $-9.08 \mathrm{e}+006$ & -127 \\
\hline
\end{tabular}

The output binding conformation of the ligand XPX in the hydrophobic ligand binding pocket of LprG protein was visualized using Chimera software (Figure $1(\mathrm{a}-\mathrm{b})$ ).

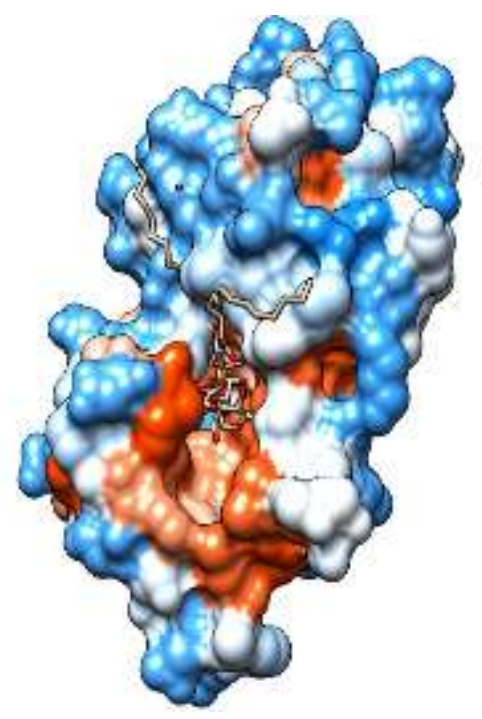

Figure-1 (a): Pictorial representation of the hydrophobicity surface view of the docked LprG and XPX complex. The hydrophobic region are represented by orange color, the hydrophilic surface by blue and neutral surface

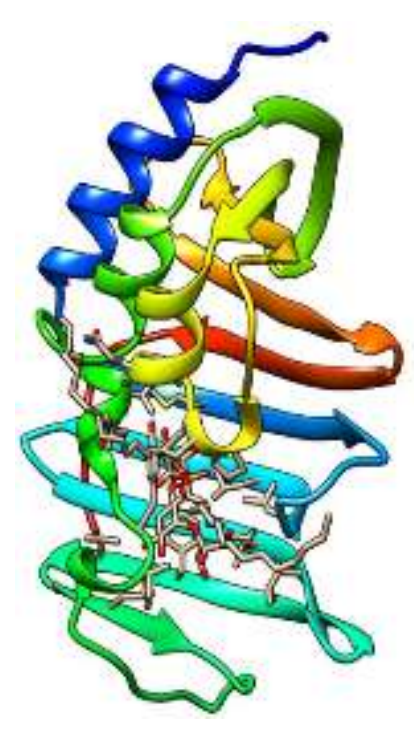

Figure 1-(b): Pictorial representation of the secondary structure of the docked LprG (protein) and XPX (Ligand) complex.

Triacylated glycolipid (PIM2) was used as a positive control for the above study. The predicted binding free energy and its corresponding DSX value of XPX were almost identical to that of the PIM2. Hence, we propose from our current understanding that the compound XPX can be a potential inhibitor of the agonist activity of the LprG protein that leads to TLR2 mediated immune evasion within host macrophages, causing virulence and latency in tuberculosis infection.

Toxicity studies. The screened ligands were further screened for their toxic properties. Table 4 shows the results of ACD/I-Lab toxicity analysis of the drug-like analogs of acylated glycolipid. It was observed that $\mathrm{XPX}$ an analog of triacylated glycolipid was identified as a non-toxic chemical entity when compared to DSU, FUG, and UDG. Both DSU and UDG were predicted to be carcinogenic agents since the probability of positive AMES test for NII and MNY were 0.95 and 0.91, respectively. AMES test is formally a biological assay to evaluate the potential of chemical compounds to cause mutation in DNA [24]. The chemical analog FUG, on the other hand, was predicted to be an endocrine disruptor since OX5 was predicted to be a binder of Estrogen Receptor alpha (ER $\alpha)$. ER $\alpha$ is a type of estrogen receptor, which get activated by the sex hormone estrogen [25-27]. The probability of toxic effect of DSU, FUG and MNY on the gastrointestinal system, lungs, blood, kidney, and blood were comparably higher than XPX. 
It is noteworthy to state that XPX chemical analogs of triacylated glycolipid which is an agonist molecule of triacylated glycolipid can prove to be the best-fit antagonist of LprG protein.

Table 4. ACD/I-Lab toxicity properties analysis of the drug-like analogs of acylated glycolipids

\begin{tabular}{|c|c|c|c|c|c|c|c|c|c|}
\hline \multirow{2}{*}{$\begin{array}{l}\text { Chemical } \\
\text { Molecule }\end{array}$} & \multirow{2}{*}{$\begin{array}{l}\text { AMES } \\
\text { Test } \\
\text { [Carcinog } \\
\text { enic] }\end{array}$} & \multirow{2}{*}{$\begin{array}{l}\text { Endocrin } \\
\boldsymbol{e} \\
\text { disruptio } \\
n\end{array}$} & \multirow{2}{*}{$\begin{array}{l}\text { Genoto } \\
\text { xicity } \\
\text { Hazard }\end{array}$} & \multicolumn{6}{|c|}{ Probability of effect on } \\
\hline & & & & $\begin{array}{l}\text { Blo } \\
\text { od }\end{array}$ & $\begin{array}{l}\text { Cardiovasc } \\
\text { ular } \\
\text { system }\end{array}$ & $\begin{array}{l}\text { Gastrointes } \\
\text { tinal } \\
\text { System }\end{array}$ & $\begin{array}{l}\text { Kidn } \\
\text { ey }\end{array}$ & $\begin{array}{l}\text { Liv } \\
\text { er }\end{array}$ & $\begin{array}{l}\text { Lun } \\
\text { gs }\end{array}$ \\
\hline$D S U$ & Positive & Negative & $\begin{array}{l}\text { Positiv } \\
e\end{array}$ & 0.65 & 0.30 & 0.89 & 0.44 & $\begin{array}{l}0.3 \\
4\end{array}$ & 0.70 \\
\hline$F U G$ & Negative & Positive & $\begin{array}{l}\text { Negativ } \\
e\end{array}$ & 0.66 & 0.73 & 0.75 & 0.24 & $\begin{array}{l}0.1 \\
5\end{array}$ & 0.6 \\
\hline$X P X$ & Negative & Negative & $\begin{array}{l}\text { Negativ } \\
e\end{array}$ & 0.21 & 0.23 & 0.46 & 0.29 & $\begin{array}{l}0.1 \\
8\end{array}$ & 0.52 \\
\hline$U D G$ & Positive & Positive & $\begin{array}{l}\text { Negativ } \\
e\end{array}$ & 0.39 & 0.75 & 0.85 & 0.46 & 0.1 & 0.36 \\
\hline
\end{tabular}

PAIN-Remover Assay. PAINS-Remover is designed and constructed to remove the Pan Assay Interference Compounds (PAINS) from screening libraries and for their exclusion in bioassays. In this study, we found that XPX analog of triacylated glycolipid passed the bell and Holloway filter.

4. Conclusion. Discovering antagonists to regulate the function of LprG protein as an agonist of TLR2 mediated immune evasion in tuberculosis infection in humans will offer several avenues in the field drug discovery against tuberculosis. In this context, we were successful in identifying four drug-like compounds using ligand-based virtual screening and docking protocol. All of these compounds, DSU, FUG, XPX and DUG have a similar affinity for LprG protein, as established by the minimum free binding energy values. Furthermore, DSX based binding energy analysis showed that all the four screened compounds are comparatively similar to the agonist molecule (PIM2) in terms of negative value (affinity). However, the free binding energy, DSX value and toxic properties for XPX are better than its counterpart ligand molecules. Hence, we propose that predicted molecule (XPX) is a potential lead molecule as an antagonist of LprG protein. Further, in vitro biological assays for XPX is needed to be performed to establish its efficacy in preventing molecular evasion mechanism of MTB within host macrophages. This study shall contribute immensely to the development of a novel class of ligands against tuberculosis that will boost the pharmaceutical sector in processing the lead compound for clinical trials.

\section{REFERENCES}

[1] WHO. (2013). Global Tuberculosis Report 2013. World Health Organization, 306. http://doi.org/10.3917/spub.092.0139

[2] Billones, J. B., Carrillo, M. C. O., Organo, V. G., MacAlino, S. J. Y., Emnacen, I. A., \& Sy, J. B. A. (2013). Virtual screening against Mycobacterium tuberculosis lipoate protein ligase B (MtbLipB) and in Silico ADMET evaluation of top hits. Oriental Journal of Chemistry, 29(4), 1457-1468. http://doi.org/10.13005/ojc/290423

[3] Drage, M.G., Tsai, H.C., Pecora, N.D., Cheng, T.Y., Arida, A.R., Shukla, S., Rojas, R.E., Seshadri, C., Moody, D.B., Boom, W.H., Sacchettini, J.C., and Harding, C.V. 2010. Mycobacterium tuberculosis lipoprotein LprG (Rv1411c) binds triacylated glycolipid agonists of Toll-like receptor 2. Nature Structural Molecular Biology, 17(9): 1088-1095.

[4] Bigi, F., Gioffré, A., Klepp, L., Santangelo, M.P., Alito, A. et al. 2004. The knockout of the lprG-Rv1410 operon produces strong attenuation of Mycobacterium tuberculosis. Microbes Infection, $6: 182-187$. 
[5] Farrow, M. F., \& Rubin, E. J. (2008). Function of a mycobacterial major facilitator superfamily pump requires a membrane-associated lipoprotein. Journal of Bacteriology, 190(5), 1783-1791. http://doi.org/10.1128/JB.01046-07

[6] Bigi, F., Alito, A., Romano, M. I., Zumarraga, M., Caimi, K., \& Cataldi, A. (2000). The gene encoding P27 lipoprotein and a putative antibiotic-resistance gene form an operon in Mycobacterium tuberculosis and Mycobacterium bovis. Microbiology, 146(4), 1011-1018.

[7] Gehring, A. J., Dobos, K. M., Belisle, J. T., Harding, C. V., \& Boom, W. H. (2004). Mycobacterium tuberculosis LprG (Rv1411c): A Novel TLR-2 Ligand That Inhibits Human Macrophage Class II MHC Antigen Processing. The Journal of Immunology, 173(4), 2660-2668. http://doi.org/10.4049/jimmunol.173.4.2660

[8] Payne, D. J., Gwynn, M. N., Holmes, D. J., \& Pompliano, D. L. (2007). Drugs for bad bugs: confronting the challenges of antibacterial discovery. Nat Rev Drug Discov, 6(1), 29-40. Retrieved from http://dx.doi.org/10.1038/nrd2201

[9] Ambur, O. H., Davidsen, T., Frye, S. A., Balasingham, S. V., Lagesen, K., Rognes, T., \& Tønjum, T. (2009). Genome dynamics in major bacterial pathogens. FEMS Microbiology Reviews, 33(3), 453-470. http://doi.org/10.1111/j.1574-6976.2009.00173.x

[10] Ekins, S., Freundlich, J. S., Choi, I., Sarker, M., \& Talcott, C. (2011). Computational Databses, Pathway and Cheminformatics Tools for Tuberculosis Drug Discovery. Trends Microbiol., 19(2), 6574. http://doi.org/10.1016/j.tim.2010.10.005.Computational

[11] García-García, A., Gálvez, J., de Julián-Ortiz, J. V., García-Domenech, R., Muñoz, C., Guna, R., \& Borrás, R. (2005). Search of chemical scaffolds for novel antituberculosis agents. Journal of Biomolecular Screening: The Official Journal of the Society for Biomolecular Screening, 10, 206-214. http://doi.org/10.1177/1087057104273486

[12] Alejandro Speck Planche, Marcus Tulius Scotti, América García López, Vicente de Paulo Emerenciano, E. M. P. U. (2009). Design of novel antituberculosis compounds using graph-theoretical and substructural approaches. Molecular Diversity, 13, 445.

[13] Koul, A., Arnoult, E., Lounis, N., Guillemont, J., \& Andries, K. (2011). The challenge of new drug discovery for tuberculosis. Nature, 469(7331), 483-490. Retrieved from http://dx.doi.org/10.1038/nature09657

[14] Kaneko T1, Cooper C, M. K. (2011). Challenges and opportunities in developing novel drugs for TB. Future Med Chem, 3(11), 1373-400.

[15] R., V. (2013). MDR-TB has new drug foe after fast-track approval. JAMA, 309(5), 430.

[16] Ballester, P. J., \& Richards, W. G. (2007). Ultrafast shape recognition for similarity search in molecular databases. Proceedings of the Royal Society A: Mathematical, Physical and Engineering Sciences, 463(2081), 1307-1321. http://doi.org/10.1098/rspa.2007.1823

[17] Pedro J. Ballester, Paul W. Finn, W. G. R. (2009). Ultrafast shape recognition: Evaluating a new ligand-based virtual screening technology. Journal of Molecular Graphics and Modelling, 27(7), 836845.

[18] Pedro J. Ballester, W. G. R. (2007). Ultrafast shape recognition to search compound databases for similar molecular shapes. Journal of Computational Chemistry, 28(10), 1711-1723.

[19] Schreyer, A. M., \& Blundell, T. (2012). USRCAT: Real-time ultrafast shape recognition with pharmacophoric constraints. Journal of Cheminformatics, 4(11), 1. http://doi.org/10.1186/1758-2946-4-27

[20] Trott, O., \& Olson, A. (2010). NIH Public Access. Journal of Computational Chemistry, 31(2), 455461. http://doi.org/10.1002/jcc.21334.AutoDock

[21] Klebe, G. N. and G. (2011). DSX: A Knowledge-Based Scoring Function for the Assessment of Protein-Ligand Complexes. Journal of Chemical Information and Modeling, 51(10), 2731-2745.

[22] Jayme L. Dahlin†ћ, J. Willem M. Nissink§, Jessica M. Strasser\|, Subhashree Francis\|, LeeAnn Higgins $\perp$, Hui Zhou\#, Zhiguo Zhang\#, and M. A. W. (2015). PAINS in the Assay: Chemical Mechanisms of Assay Interference and Promiscuous Enzymatic Inhibition Observed during a Sulfhydryl-Scavenging HTS. Journal of Mechanical Chemistry, 58(5), 2091-2113.

[23] Lipinski, C. A. (2000). Drug-like properties and the causes of poor solubility and poor permeability. Journal of Pharmacological and Toxicological Methods, 44(1), 235-249.

[24] Mortelmans, Kristien, E. Z. (2000). The Ames Salmonella/microsome mutagenicity assay. Mutation Research/Fundamental and Molecular Mechanisms of Mutagenesis, 455(1-2), 29-60. 
[25] Greene GL, Gilna P, Waterfield M, Baker A, Hort Y, S. J. (1986). Sequence and expression of human estrogen receptor complementary DNA. Science, 231(4742), 1150-1154.

[26] Khasawneh, R., \& Kornreich, R. (1809). R eseaRch a Rticle R eseaRch a Rticle. Pharmacogenomics, 3(4), 781-791. http://doi.org/Article

[27] Walter, P., Green, S., Greenet, G., Krust, A., Bornert, J.-M., Jeltsch, J.-M., ... Chambon, P. (1985). Cloning of the human estrogen receptor cDNA (Agtll expression screening/oligonucleotide screening/in vito translation/hybrid-selection/monoclonal antibody). Biochemistry, 82(December), 7889-7893. http://doi.org/10.1073/pnas.82.23.7889 